\title{
A national survey of diagnostic tests reported by UK community optometrists for the detection of chronic open angle glaucoma
}

\author{
Joy Myint1, David F Edgar1, Aachal Kotecha1,2, Ian E Murdoch3and John G Lawrenson1 \\ 1 Henry Wellcome Laboratories for Vision Sciences, Department of Optometry and Visual Science, \\ City University London, London, UK,
}

2NIHRBMRC for Ophthalmology, Moorfields Eye Hospital NHS Foundation Trust and UCL Institute of Ophthalmology, London, UK, and

3Glaucoma Unit, Moorfields Eye Hospital, London, UK

\begin{abstract}
Purpose: In the UK, the majority of cases of chronic open angle glaucoma are detected by community optometrists following a routine sight test. However, there is potential for variability in case finding strategies used. The aim of this study was to carry out a national web-based survey to determine current diagnostic tests used by optometrists in glaucoma case finding.

Methods: Optometrists on the Association of Optometrists (AOP) electronic database were invited to participate. The survey was open for 16 weeks between April and July 2008.

Results: A total of 1875 optometrists were eligible to enter the survey, of which1264 answered the questions relating to diagnostic equipment. Respondents were asked to indicate their usual method of examining the optic nerve head. Direct ophthalmoscopy only was used by $25 \%$ with the majority (62\%) using a combination of direct and slit-lamp binocular indirect methods. The vast majority of optometrists (78\%) used non-contact tonometry to measure intra-ocular pressure, with only $16 \%$ routinely using a Goldmann or Perkins applanation tonometer. The perimeter most frequently used was either one of the Henson range of instruments (39\%) or the Humphrey Field Analyser (22\%).A smaller number of optometrists $(<5 \%)$ had access to more specialised imaging equipment, such as HRT, GDx or OCT.
\end{abstract}

Conclusions: The results of the survey demonstrate that UK optometrists are well equipped to carry out case finding for chronic open angle glaucoma, although there is a lack of standardisation with respect to equipment used. 


\section{Introduction}

Chronic open angle glaucoma (COAG) is an insidious disease affecting 1-2\% of the population aged 40-65 years, rising to $7 \%$ in those over 75 . Sufferers are asymptomatic and may be unaware of glaucomatous visual field loss, which can lead to late presentation. In the UK, approximately $10 \%$ of blind and partially sighted registrations are attributed to glaucoma.1 In the absence of a formal screening programme for COAG, detection of the disease relies on case finding in individuals consulting community optometrists. In England, Wales and Northern Ireland, NHS-funded Sight Tests are available to everyone over 60 years and those over 40 with a family history of glaucoma through the General Ophthalmic Services (GOS). In Scotland NHS-funded Sight Tests are available to all. Guidance for all UK optometrists has been published by their professional body (College of Optometrists), regarding the 'examination of patients at risk from glaucoma',2 recommending the usual triad of screening tests; assessment of the optic nerve head, tonometry and central visual field assessment. However, the choice of equipment and the actual case finding protocol used is at the discretion of the individual optometrist. As a result, significant variation in glaucoma case finding practices has been reported.3,4

Twenty years ago a large survey was conducted on behalf of the International Glaucoma Association (IGA)to examine aspects of screening and referral for glaucoma by optometrists in England and Wales.5-8Since that time, there has not been an equivalent in-depth national survey of glaucoma case finding practices. The present study reports the results of a large online survey of members of the Association of Optometrists (AOP) conducted in2008. The survey is particularly timely given the recent Health Technology Assessment (HTA) review considering the clinical and cost effectiveness of population-based screening for COAG.9 The conclusion of the review was that population screening was not cost effective, and by implication that detection of the disease would continue to depend on opportunistic case finding. However there was an acknowledgement that glaucoma detection could be improved by increasing the uptake of sight tests and improving the standard of optometric assessment. The aim of this study was to carry out a national web-based survey to determine current diagnostic tests used by optometrists in glaucoma case finding.

\section{Methods}

A survey to investigate UK optometrists' current practice in the detection of COAG was developed. The survey was entirely web-based and hosted by a US provider of online surveys (Survey Monkey; http://www.surveymonkey.com).The survey was piloted on 100 optometrists selected using a convenience sampling technique. Based on their feed-back, minor amendments were made and the final survey was opened in April 2008. There was no fixed closing date for the survey, which remained open until there were wo consecutive days without any responses. This occurred in July 2008 after the survey had been open for16 weeks. All optometrists on the Association of Optometrists(AOP) electronic database were invited to participate. The AOP represents the professional interests of UK optometrists. Seven thousand four hundred and thirtye mails were sent to AOP members, but this total included non-practicing and retired optometrists, and non-community practitioners (e.g. hospital-based optometrists). There were also some duplicate email addresses. The email invited members to participate in the survey online via a hyperlink to the website. Two reminders were sent and news features promoting the survey were included in AOP membership publications. The survey was anonymous and no incentives or feed-back were offered. 
It consisted of 27 forced choice or free-text questions covering different aspects of optometric practice.

\section{Mode of practice (nine questions)}

The survey was restricted to community-based optometrists and Question 1 established respondents' mode of practice. Those practicing outside primary care community optometry (e.g. hospital optometrists) and non-prac-ticing optometrists were asked to proceed no further.

\section{Strategies for glaucoma detection (two questions)}

Section 2 consisted of two free-text boxes, with the former relating to optometrists' criteria for glaucoma case-finding and the latter to perceived barriers to effective detection.

\section{Equipment used for glaucoma detection and practice organisation (nine questions)}

Section 3 aimed to establish the extent of pre-screening testing equipment available in the practice, any involvement in local glaucoma schemes, and whether the individual had completed any further postgraduate training specifically related to glaucoma.

\section{Strategies for glaucoma referral (five questions)}

Section 4 asked for the total number of referrals made by the optometrist, how many of these were related to COAG, to whom referrals were made, and what information was included in the referral.

\section{Personal/Demographic information (two questions)}

Respondents were invited to give their gender and year of registration.

There were four questions relating to optometric instrumentation, which formed the basis for this paper. These questions asked respondents to indicate via forced choice options which equipment they used for glaucoma detection i.e. for field testing, for optic nerve head examination and for the measurement of intra-ocular pressures. An additional question inquired whether participants possessed any more 'specialist' equipment from a pre-determined list. The authors' initial selection of the options for equipment was based on their knowledge of UK optometric pre- and postregistration training and practice. These options were refined following feedback from the pilot study.

This research was approved by the City University London Research and Ethical committee. The explanatory email sent to all potential optometrist participants, which included the hyperlink to the survey, contained full details of the research. Participation in the survey was completely voluntary and it was assumed that entering the survey constituted informed consent. 


\section{Results}

A total of 2044 optometrists entered the survey, equating to a response rate of $27.5 \%$ of those UK registered optometrists who received an email. One thousand eight hundred and seventy-five of these (92\%) were currently working as community practitioners and therefore eligible to complete the survey. The online format allowed participants to exit at any time and 611 of those starting the survey dropped out before completing the section relating to diagnostic equipment, the majority exiting at an earlier unrelated free-text question. An analysis of the demo-graphics of this group did not reveal any significant differences when compared to the 1264 (response rate of $17 \%$ ) who completed the survey (Chi-square $p>0.05$ ). These 1264 respondents represent $11 \%$ of the total number of optometrists on the General Optical Council(GOC) register at the time of the survey. Of the 1264 respondents who completed the equipment section(Table 1), 57\% were from independent practices, 23\%worked in 'multiples' (familiar High Street optometrists)and the remainder were mainly locum optometrists who did not hold a residency post. Of the respondents, $46.9 \%$ were male and $53.1 \%$ were female, similar to the $48.2 \%$ male and $51.8 \%$ female distribution of GOC registrants for the year 2007-2008.10 Similarly the percentage of respondents from England (83\%), Scotland (8.2\%), Wales(5.9\%) and Northern Ireland (2.6\%) was similar to the distribution of GOC registrants $(82 \%, 9.5 \%, 4.8 \%$, and $4.1 \%$ respectively) in those countries.

Table 1 The breakdown of optometrists by country according to the GOC 2007/8 Annual Report,10according to AOP demographics, and among survey respondents

\begin{tabular}{|l|l|l|l|}
\hline & GOC n(\%) & AOP n (\%) & Survey respondents n (\%) \\
\hline England & $9052(81.6)$ & $8973(82.5)$ & $1053(83.3)$ \\
\hline Scotland & $1053(9.5)$ & $920(8.5)$ & $104(8.2)$ \\
\hline Wales & $534(4.8)$ & $567(5.2)$ & $74(5.9)$ \\
\hline Northern Ireland & $455(4.1)$ & $415(3.8)$ & $33(2.6)$ \\
\hline Total & 11094 & 10875 & 1264 \\
\hline
\end{tabular}

The equipment questions were divided into; methods for examining visual fields, methods for examining the optic nerve head, methods for measuring intraocular pressure (IOP) and a final section on more specialised instrumentation.

The first question asked 'which field testing equipment is normally used routinely for primary open angle glaucoma detection in the principal practice?' The choices were 'Humphrey, Henson, Dicon, Frequency Doubling Technology Perimeter (FDT), Friedmann Visual Field Analyser (VFA), Oculus Easyfield and Other', the final option incorporating a free-text option to indicate the instrument used. The survey revealed that a wide range of perimeters were used, however the instruments most frequently used were either one of the Henson range of instruments (39\%) or the Humphrey Field Analyser(22\%) (Table 2). 
Table 2 Relative frequency of perimeter use by community optometrists

\begin{tabular}{|l|l|l|}
\hline & $\begin{array}{l}\text { Frequency of respondents }\left(\%^{*}\right) \\
\text { in 2008 survey } \mathrm{n}=1264\end{array}$ & $\begin{array}{l}\text { Frequency of respondents (\%) } \\
\text { in 1989 IGA survey } \mathrm{n}=101\end{array}$ \\
\hline Henson & 39 & 34 \\
\hline Humphrey & 22 & 4 \\
\hline Dicon & 15 & N/A \\
\hline FDT & 12 & N/A \\
\hline Oculus Easyfield & 6 & N/A \\
\hline VFA & 2 & 40 \\
\hline Other & 4 & $23^{\wedge}$ \\
\hline
\end{tabular}

* Percentages have been rounded to the nearest whole number resulting in some percentage totals differing from 100.

^ Tangent screens (Fincham Sutcliffe, Bjerrum). FDT, Frequency Doubling Technology Perimeter; VFA, Friedmann Visual Field Analyzer.

Respondents were asked to indicate their usual method of examining the optic nerve head. Options were, 'Direct', 'Indirect', 'Direct and Indirect' or 'Other please specify'(Table 3).

Table 3. Relative frequency of the different methods of optic nervehead examination by community optometrists

\begin{tabular}{|l|l|}
\hline & $\begin{array}{l}\text { Frequency ofrespondents }(\% *) \\
\text { in 2008 survey } \mathrm{n}=1264\end{array}$ \\
\hline Direct and indirect & 62 \\
\hline Direct only & 25 \\
\hline Indirect only & 11 \\
\hline Digital imaging & 1 \\
\hline
\end{tabular}

*Percentages have been rounded to the nearest whole number result-ing in some percentage totals differing from 100.

The majority (62\%) used a combination of direct and indirect. In a supplementary question $43 \%$ of 355 respondents stated that they additionally used a fundus photographic imaging system for photo documentation. Respondents were asked to indicate which method they used routinely to measure intra-ocular pressures. The choices were 'Non-Contact Tonometer (NCT), Pulsair, Perkins, Goldmann, Tonopen, Schiotz, I-Care and Other(please specify)'. Non-contact methods were most popular(78\%), with respondents mainly using a hand-held Keeler Pulsair (36\%) or one of the table-mounted noncontact tonometers (NCT) (43\%). Of those $16 \%$ using contact applanation tonometry, $11 \%$ used a Perkins and $5 \%$ a Goldmann applanation tonometer (Table 4). 
Table 4. Relative frequency of the use of different tonometers by community optometrists

\begin{tabular}{|l|l|l|}
\hline & $\begin{array}{l}\text { Frequency of respondents (\%) } \\
\text { in 2008 survey } \mathrm{n}=1264\end{array}$ & $\begin{array}{l}\text { Frequency of respondents (\%) } \\
\text { in 1989 IGA survey } \mathrm{n}=186\end{array}$ \\
\hline Table-mounted NCT & 43 & 55 \\
\hline Pulsair & 36 & 19 \\
\hline Perkins & 11 & $26^{*}$ \\
\hline Goldmann & 5 & \\
\hline Tonopen & 1 & N/A \\
\hline i-care & 4 & N/A \\
\hline Schiotz & 0 & N/A \\
\hline Other & 0 & N/A \\
\hline
\end{tabular}

* Combined frequency for Goldmann and Perkins tonometers.

The final question asked 'Does your principal practice possess any of the following specialist equipment?' and respondents were asked to indicate the availability of equipment from the following list 'Optical Coherence Tomography (OCT), Scanning Laser Polarimeter (GDX), Pachymeter, Heidelberg Retina Tomograph (HRT), Goniolens, and Other (please specify)'. A breakdown of responses is given in Table 5 .

Table 5. Relative frequency of the availability of specialist equipment in community optometric practice

\begin{tabular}{|l|l|}
\hline & $\begin{array}{l}\text { Frequency of respondents (\%) } \\
\text { in 2008 survey }\end{array}$ \\
\hline Goniolens & 12 \\
\hline Pachymeter & 7 \\
\hline GDx & 3 \\
\hline HRT & 2 \\
\hline OCT & 2 \\
\hline Other & 0 \\
\hline
\end{tabular}

GDx, Scanning Laser Polarimeter; HRT, Heidelberg Retina Tomograph; OCT, Optical Coherence Tomography

\section{Discussion}

In the UK, the current practice of glaucoma detection depends largely on community optometrists, who are responsible for over $90 \%$ of COAG referrals to secondarycare.11However, the reliance on optometrists means that screening is opportunistic and only performed on a self-selected population. Although 5.8 million NHS sight tests were conducted on patients over 60 in England and Wales in the year ending March 2010, 12significant numbers of the population 'at risk' of COAG do not consult optometrists. Moreover, higher rates of late presentation are associated with living in areas of high social deprivation where optometrists' premises are poorly represented.13Nonetheless, knowledge of the case-finding strategies used by community optometrists is of significant public health importance. The results of the present study suggest that optometrists 
are well-equipped to per-form the usual triad of tests (IOP, optic nerve head assessment and visual fields) necessary to detect glaucoma and significant developments in clinical practice have occurred in the years since the last large-scale national survey of optometrists (the IGA survey) conducted20 years ago.5-8These comparisons with the IGA study cannot take into account the different modes of delivery of the two surveys (paper-based in the IGA survey vs computer-based) nor the geographical variations in the scope of the surveys (targeting specific areas in the IGA survey vs national) which may lead to a different demo-graphic distribution among respondents.

\section{Visual field testing}

At the time of the IGA survey (1990) only half of optometrists had access to an automated perimeter.7The routine use of visual field testing equipment in optometric practice increased throughout the 1990s and by 1998 it was reported that one-third of practitioners were performing routine visual fields in patients over 40 years of age.14Virtually all optometrists (>95\%) in the present survey reported that they had access to an appropriate automated perimeter that was used for the detection of glaucoma. Although respondents had access to a range of instruments, the majority used either one of the Henson range of instruments (39\%) or the Humphrey Field Analyser (22\%). In routine practice, visual field testing is only per-formed if deemed clinically necessary; however College of Optometrists guidance 2 states that an assessment of the visual field should be performed on all patients at risk of COAG. Although published audits of referrals for COAG have shown that information on visual fields is provided in $67-82 \%$ of referrals,15,16a recent study, using a standardised patient methodology, found that visual fields were assessed by only $36 \%$ of optometrists in a patient at risk of developing COAG.4Counterintuitively, it has been shown that the increased adoption of perimetry by optometrists has not necessarily led to an improvement in diagnostic accuracy.16,17 A possible explanation is that the GOS contract in England and Wales does not remunerate optometrists for repeat testing and so optometrists may not ascertain that a defect is reproducible before referral. Furthermore the increased use of visual field screening may identify non-glaucomatous field defects. Another question in the survey asked respondents to give details in free text form of their case-finding strategies for patients with suspect glaucoma. Full details of responses will be presented in another paper. However, of relevance to the current paper is whether optometrists surveyed used suprathreshold or threshold (full threshold or SITA) paradigms when assessing visual fields. Sixteen percent of our respondents referred to a specific testing strategy. Of these, $6.3 \%$ referred specifically to supra-threshold field testing strategies and $9.7 \%$ referred to threshold or full threshold strategies. This preference for threshold strategies (61\%) over suprathreshold (39\%) is encouraging as it indicates that optometrists recognise the value of a more in-depth field investigation in patients with suspect glaucoma.

\section{IOP measurement}

The current survey revealed that $79 \%$ of optometrists used a non-contact tonometer for IOP measurement, specifically a table-mounted NCT (43\%) or a hand-held Keeler Pulsair (36\%). This finding is consistent with previous clinical practice surveys.8,18Non-contact tonometry gained popularity in optometric practice during the 1980s. It had obvious advantages as a screening test for glaucoma: the test was quick and easy to perform, did not require anaesthetic eye drops, was acceptable to patients and could be delegated to optical assistants. Non-contact tonometry is associated with high levels of sensitivity and specificity for detecting IOPs $>21 \mathrm{mmHg} .19$ However, 
instruments require regular maintenance and accuracy is compromised when fewer than the recommended number of readings are per-formed.20 Recently, the Colleges of Optometrists and Ophthalmologists have produced joint guidance on referral for glaucoma which provides advice on maximising the accuracy of non-contact tonometry.21 Surprisingly few optometrists (16\%) reported using applanation tonometry, the accepted reference standard, for routine glaucoma detection, despite the findings of a recent College of Optometrists Clinical Practice Survey showing that approximately $53 \%$ of optometrists possessed an applanation tonometer within their practice. 22 Potential barriers to the widespread adoption of applanation tonometry may include; training issues, recurring costs of the procedure and patient acceptance. Evidence from Scotland suggests that these barriers can be over-come. In 2006, a new General Ophthalmic Services (GOS) contract for Scotland required that optometrists demonstrate competence in Goldmann applanation tonometry before they could be accredited. As part of the contract a supplementary fee was negotiated to perform the test. These measures led to an increase in the number of glaucoma referrals which included information on applanation tonometry from $11.8 \%$ prior to the new contract to $50 \%$ following its introduction.23

\section{Optic nerve head assessment}

Ophthalmoscopic examination of the fundus, including the optic nerve head, is mandatory in all optometric eye examinations performed by community optometrists. However, the choice of technique is at the discretion of the optometrist. Traditionally, optometrists have used direct ophthalmoscopy through undilated pupils to examine the fundus as part of a general evaluation of the posterior pole. However, the reference standard for the assessment of the optic nerve head in glaucoma is slit lamp binocular indirect ophthalmoscopy, which provides a stereoscopic view of the optic nerve head. The majority of respondents in the survey (62\%) used a combination of direct and indirect, with $25 \%$ using direct only. Although increasingly optometric practices are incorporating fundus imaging into a general eye examination ( $43 \%$ in our sample), fewer than $2 \%$ were specifically using fundus imaging as their only method of assessing the optic nerve head for the purposes of glaucoma detection. This finding is consistent with the study of Shah et al. using a standardised patient considered to be at risk of glaucoma. 4 The use of slit-lamp binocular indirect ophthalmoscopy has increased amongst optometrists in recent years. It is now a core competency for GOC registration and is formally assessed by the College of Optometrists in professional qualifying examinations.

\section{Specialised equipment for the detection of COAG}

The survey also obtained data on more specialist equipment used by optometrists for glaucoma detection. In this question respondents were invited to select as many or as few instruments as applied, with the result that some will have selected two or more items of equipment from the list supplied. Fewer than $7 \%$ of respondents possessed specialist imaging devices (e.g. GDx, or OCT) that quantify nerve fibre loss in glaucoma. Significantly, only $7 \%$ of optometrists had access to a pachymeter and $12 \%$ had access to a gonio lens. The recently published NICE guideline 24 on the diagnosis and management of glaucoma states that all patients with suspect COAG or ocular hypertension should have pachymetry and gonioscopy at diagnosis. Pachymetry and gonioscopy are not core competencies for optometrists although since publication of the guideline both techniques have been given prominence at optometry continuing professional development events. 


\section{Limitations of the study.}

It is important when considering the results of a survey of this type to address the potential for response bias. The AOP provides professional indemnity insurance for approximately $90 \%$ of UK optometrists (AOP, personal communication) and therefore its membership database reflects the demographics of the GOC register. Optometrists were invited to participate in the survey via email and, as a result, only those AOP members who had provided a current email address were contacted, which may have biased the sample. However the demographics of those responding to the survey were consistent with the GOC register in terms of age and gender, with a similar stratification by geographic location (Table 1).

A further potential source of bias may be introduced by the self-selection inherent in surveys of this nature. Itis probable that those who elected to participate, even though all input was anonymous, are likely to include a higher proportion of better motivated practitioners who feel most confident about the equipment that they use for glaucoma detection. It is possible that this self-selection will lead to some overestimation of the quality of equipment found in practices.

Although the wording of questions in the survey asked about diagnostic equipment 'used routinely in COAG detection', it is possible that self-reported practices may not reflect actual practices, particularly with respect to discretionary tests. 4 A recent study has demonstrated that UK optometrists perceive barriers that affect their case finding in patients at risk of glaucoma, primarily caused by financial and time constraints imposed by the current GOS contract, which may compromise the quality of their clinical assessment. 25

A total of 1264 respondents answered the questions on equipment discussed in this paper. This represents $17 \%$ of those $A O P$ members who received emails and $11 \%$ of the total number of optometrists on the GOC register at the time of the survey. Not all those on the GOC register would have been eligible to complete the survey, for example hospital optometrists would have been excluded. Nevertheless, these 1264 optometrists represent $<15 \%$ of the total number of optometrists on the GOC register who were eligible to complete the survey. It is also possible that there was some 'double-counting' where more than one respondent reported results from the same practice. Therefore, caution should be exercised when extrapolating the results and conclusions from this survey to UK primary care optometrists as a whole.

In April 2009 guidelines commissioned by the National Institute for Health and Clinical Excellence regarding' diagnosis and management of chronic open angle glaucoma and ocular hypertension' were released. Though only 'guidelines' per se, advice from professional bodies to the optometric profession strongly suggests that the recommendations are likely to be regarded by optometrists as setting professional standards. The survey discussed in this paper was conducted prior to the introduction of the NICE guidelines, but the authors suggest the guideline would have minimal impact on the instrumentation present within optometric practice. There is a possibility that there may be an increase in the use of applanation tonometers, but research suggests that an increase in referral rates has been the reaction of the profession. 26 


\section{Conclusion}

The results of the present study demonstrate that UK optometrists are well equipped for COAG case finding. The study also provides evidence that optometrists' skills and scope of practice in the detection of glaucoma have evolved since the last national survey, which was commissioned by the IGA in the late 1980s. There is a lack of standardisation of the case-finding protocol and the tests performed are at the discretion of the optometrist, thereby compromising diagnostic accuracy. Attempts at standardisation using accredited community optometrists in a variety of referral refinement/shared care models appear to be safe and clinically effective alternatives.27,28 However, it is too early to determine whether these models are cost effective.

\section{Acknowledgements}

Miss Myint is funded through an unrestricted grant from Pfizer Ophthalmology. Dr Kotecha receives a proportion of her funding from the Department of Health's National Institute for Health Research Biomedical Research Centre for Ophthalmology at Moorfields Eye Hospital NHS Foundation Trust and the UCL Institute of Ophthalmology. The views expressed in this publication are those of the authors alone.

\section{References}

1. Bunce C \& Wormald R. Causes of blind certifications in England and Wales: April 1999-March 2000. Eye 2008; 22:905-911.

2. College of Optometrists. Code of Ethics and Guidelines for Professional Conduct, Section D3 examining patients at risk from glaucoma. http://www.collegeoptometrists.org/en/utilities/document-summary.cfm/docid/D15DFBC3-5146-432DBEFE9681ED555393, accessed 18/10/10.

3. Scully ND, Chu L, Siriwardena D, Wormald R \& Kotecha A. The quality of optometrists' referral letters for glaucoma. Ophthalmic Physiol Opt 2009; 29: 26-31.

4. Shah R, Edgar DF, Spry PG et al. Glaucoma detection: the content of optometric eye examinations for a presbyopic patient of African racial descent. Br J Ophthalmol 2009; 93:492-496.

5. Tuck MW \& Crick RP. Screening for glaucoma: age and sex of referrals and confirmed cases in England and Wales.Ophthalmic Physiol Opt 1992; 12: 400-404.

6. Tuck MW \& Crick RP. Relative effectiveness of different modes of glaucoma screening in optometrist practice. Ophthalmic Physiol Opt 1993; 13: 227-232.

7. Tuck MW \& Crick RP. Use of visual field tests in glaucoma by optometrists in England and Wales. Ophthalmic Physiol Opt 1994; 14: 227-231.

8. Tuck MW \& Crick RP. Non-contact tonometry: optometrists current practice in England and Wales. Ophthalmic Physiol Opt 1994; 14: 347-350. 
9. Burr JM, Mowatt G, Hernandez $R$ et al. The clinical effectiveness and cost-effectiveness of screening for open angle glaucoma: a systematic review and economic evaluation. Health Technol Assess 2007; 11: 1-190.

10. GOC Annual Report 2007-8.

http://www.optical.org/en/news_publications/Publications/annual_reports_archive.cfm, accessed 18/10/10.

11. Bowling B, Chen SDM \& Salmon JF. Outcomes of referrals by community optometrists to a hospital glaucoma service. Br J Ophthalmol 2005; 89: 1102-1104.

12. General Ophthalmic Services Activity Statistics for England and Wales, NHS Information Centre, Dental and Eye Care Team. 2010.

http://www.ic.nhs.uk/webfiles/publications/Primary\%20Care/Eye\%20care/gosactivity0910/General _Ophthalmic_Services_Activity_Statistics_for_England_and_Wales_2009_10.pdf, accessed 18/10/10.

13. Day F, Buchan JC, Cassells-Brown A, Fear A, Dixon R\& Wood F. A glaucoma equity profile: correlating dis-ease distribution with service provision and uptake in a population in Northern England, UK. Eye 2010; 24:1478-1485.

14. Tuck MW \& Crick RP. Glaucoma screening by optometrists: ten years on. Health Trends 1999; 30: 130-134.

15. Lash SC. Assessment of information included on the GOS18 referral form used by optometrists. Ophthalmic Physiol Opt 2003; 23: 21-23.

16. Lockwood AJ, Kirwan JF \& Ashleigh Z. Optometrists referrals for glaucoma assessment: a prospective survey of clinical data and outcomes. Eye 2010; 24: 1515-1519.

17. Vernon SA. The changing pattern of glaucoma referrals by optometrists. Eye $1998 ; 12: 854-857$.

18. Willis CE, Rankin SJ \& Jackson AJ. Glaucoma in optometric practice: a survey of optometrists. Ophthalmic Physiol Opt 2000; 20: 70-75.

19. Atkinson PL, Wishart PK, James JN, Vernon SA \& Reid F. Maximising the sensitivity and specificity of non-contact tonometry in glaucoma screening. Eye 1992; 6: 530-534.

20. Vernon SA, Jones SJ \& Henry DJ. Deterioration in the accuracy of the pulsair non-contact tonometer with use: need for regular calibration. Eye 1991; 5: 491-493.

21. Guidance on the referral of Glaucoma suspects by com-munity optometrists issued by The College of Optometrists and The Royal College of Ophthalmologists 17December 2009. Available: http://www.rcophth.ac.uk/docs/profstands/Guidance_on_the_referral_of_Glaucoma_suspects_by_ community_optometrists_Final.pdf, accessed18/10/10.

22. Medix UK \& The College of Optometrists. The College of Optometrists Clinical Practice Survey: Market Research Report. London: Medix UK, 2008. 
23. Ang GS, Ng WS \& Azuara-Blanco A. The influence of the new general ophthalmic services (GOS) contract in optometrist referrals for glaucoma in Scotland. Eye 2009;23: 351-355. Epub 2007 Nov 30.

24. National Institute for Health and Clinical Excellence(2009). Glaucoma: diagnosis and management of chronicopen angle glaucoma and ocular hypertension.

http://www.nice.org.uk/nicemedia/pdf/CG85FullGuideline.pdf,accessed 18/10/10.

25. Myint J, Edgar DF, Kotecha A, Murdoch IE \& Lawrenson JG. Barriers perceived by UK based community optometrists to the detection of primary open angle glaucoma. Ophthalmic Physiol Opt 2010; 30: 1-7.

26. Edgar D, Romanay T, Lawrenson J \& Myint J. Referral behaviour among optometrists: increase in the number of referrals from optometrists following the publication of the April 2009 NICE guidelines for the diagnosis and management of COAG and OHT in England and Wales and its implications. Optom Pract 2010; 11: 31-34.

27. Bourne RRA, French KA, Chang L, Borman AD, Hingorani M \& Newsom WD. Can a community optometrist-based referral refinement scheme reduce false-positive glaucoma hospital referrals without compromising quality of care? The community and hospital allied network glaucoma evaluation scheme (CHANGES). Eye 2010; 24:881-887.

28. Syam P, Rughani K, Vardy SJ et al. The Peterborough scheme for community specialist optometrists in glaucoma: a feasibility study. Eye 2010; 24: 1156-1164 